Case Report

\title{
Genital Schistosomiasis: A Report on Two Cases of Ovarian Carcinomas Containing Viable Eggs of Schistosoma mansoni
}

\author{
Andressa Gonçalves Amorim, ${ }^{1}$ Fernanda Alves Barbosa Pagio, ${ }^{1}$ \\ Rodrigo Neves Ferreira, ${ }^{2}$ and Antônio Chambô Filho ${ }^{1}$ \\ ${ }^{1}$ Department of Obstetrics and Gynecology, Santa Casa de Misericórdia Hospital, 143 Dr. João dos Santos Neves, \\ 29025-023 Vitória, ES, Brazil \\ ${ }^{2}$ Department of Pathology, Santa Casa de Misericórdia Hospital, 143 Dr. João dos Santos Neves Street, 29025-023 Vitória, ES, Brazil
}

Correspondence should be addressed to Andressa Gonçalves Amorim; andressaamorim88@hotmail.com

Received 4 July 2014; Revised 5 December 2014; Accepted 8 December 2014; Published 22 December 2014

Academic Editor: Hao Lin

Copyright (C) 2014 Andressa Gonçalves Amorim et al. This is an open access article distributed under the Creative Commons Attribution License, which permits unrestricted use, distribution, and reproduction in any medium, provided the original work is properly cited.

\begin{abstract}
Schistosomiasis is a parasitic infection that is highly prevalent worldwide, with a variety of species being responsible for causing the disease. In Brazil, however, the only identified species is Schistosoma mansoni. The adult parasites inhabit the blood vessels of the hepatic portal system of the main host. The disease may range from being asymptomatic to provoking liver damage or portal hypertension. Furthermore, ectopic schistosomiasis may develop, and several hypotheses have been raised to explain the occurrence of the disease. This paper describes two cases, one in a 39-year-old woman and the other in a 47-year-old woman. Both had similar symptoms of pain and abdominal distension caused by a large abdominal/pelvic mass. Histopathology of the ovary showed a mucinous cystadenocarcinoma of the intestinal type in the first patient and a papillary serous carcinoma in the second, with both tumors containing viable eggs of Schistosoma mansoni. The neoplasms probably serve as a migratory route for the adult parasites and the embolization of eggs. Nevertheless, there is insufficient evidence to confirm the malignization of a benign lesion due to the presence of Schistosoma mansoni. Few cases have been reported in the international literature on the association between ovarian schistosomiasis and neoplasms.
\end{abstract}

\section{Introduction}

Ovarian epithelial carcinoma is the second most common cancer of the female genital tract. It corresponds to $5 \%$ of all female tumors [1] and is the third cause of death from cancer in women [2].

Protective factors for ovarian cancer include parity, breastfeeding, the use of oral contraceptives, late menarche, early menopause, and surgical procedures such as hysterectomy and salpingectomy. Risk factors include the use of ovulation-inducing drugs, high estrogen and androgen levels, and genetic and environmental factors [3].

In rare cases, an association has been reported between neoplasms and schistosomiasis, with studies showing that the ovaries are affected in only $0.5 \%$ of cases of ectopic schistosomiasis [4].

Schistosomiasis caused by S. mansoni is endemic in the Caribbean islands, Middle East, South America, and Africa and can be imported to any region of the world through immigration [5]. The disease is considered a severe public health issue [6]. Between 200 and 300 million individuals are believed to be infected with $S$. mansoni worldwide. In Brazil, this figure is estimated at 4 to 6 million individuals [7]. Currently, schistosomiasis is present in almost all the Brazilian states, principally in areas of the northeastern, southeastern, and midwestern regions [8]. Various species of Schistosoma cause schistosomiasis; however, only S. mansoni has been reported in Brazil [9].

This parasitic infection is an important cause of morbidity and mortality and has been found in various organs of the body. There is generally no clinical suspicion of schistosomiasis in these lesions; indeed, in the majority of cases, the infection is only discovered by chance at histopathology [10].

Two cases are reported here in which histopathology identified viable Schistosoma mansoni (S. mansoni) eggs 
associated with an ovarian mucinous cystadenocarcinoma of the intestinal type (case \#1) and with a papillary serous carcinoma (case \#2) in patients receiving care at the Department of Obstetrics and Gynecology, Santa Casa de Misericórdia Hospital, Vitória, Espírito Santo, Brazil. The internal review board approved this report under reference number 25471214.0.0000.5065. Both patients gave their signed informed consent to the publication of the images that form part of this paper.

\section{Case Report \#1}

This patient, a 39-year-old woman, was hospitalized complaining of progressive abdominal distension and edema of the lower limbs over the previous month. She also complained of abdominal pain and frequent micturition. There were no signs of dysuria, gastrointestinal symptoms, fever, loss of appetite, or weight loss.

Physical examination showed the patient to be in an apparently good general state of health. She was well hydrated, her temperature was normal, and there were no signs of anemia, jaundice, or cyanosis. No cardiovascular or respiratory abnormalities were found. The distended abdomen presented normal bowel sounds, with a large, hardened, irregular mass extending from the pelvis to the epigastrium. Palpation of the liver and spleen revealed no abnormalities. There were no signs of ascites or enlarged lymph nodes. Gynecological examination revealed an apparently normal cervical epithelium and external os with no abnormal discharge. Digital pelvic examination showed a fibroelastic, closed cervix that was mobile and painless. Bimanual palpation revealed a large pelvic mass protruding into the Douglas pouch. The borders of the uterine fundus were unclear due to the size of the tumor.

Pelvic ultrasonography revealed a large abdominal/pelvic mass of $6,606.7 \mathrm{~cm}^{3}$, with a predominantly cystic appearance and a solid component. There was an anechoic cystic mass of $4 \mathrm{~cm}^{3}$ in volume on the right ovary. Uterine volume was $180 \mathrm{~cm}^{3}$ and endometrial thickness was $6.7 \mathrm{~mm}$. There were no signs of ascites. Doppler flow showed a low resistance index of 0.44 .

The results of supplementary tests showed CA-125 levels of $24.87 \mathrm{U} / \mathrm{mL}$, hemoglobin $10.5 \mathrm{~g} / \mathrm{dL}$, hematocrit $35.6 \%$, mean corpuscular volume (MCV) $81.2 \mathrm{fl}$, mean corpuscular hemoglobin $(\mathrm{MCH}) 27.5 \mathrm{pq}$, mean corpuscular hemoglobin concentration (MCHC) $32.2 \%$, and coefficient of variation of red cell distribution width (RDW-CV) $12.0 \%$. White blood cell count was $8,500 / \mathrm{cm}^{3}$, with $3 \%$ eosinophils $\left(255 / \mathrm{mm}^{3}\right)$.

2.1. Surgery. Exploratory laparotomy performed through a midline infraumbilical incision showed a large, predominantly cystic tumor occupying the entire abdominal/pelvic cavity, with its epicenter in the left ovary. Extraovarian lesions and signs of ascites were then noted. A hysterectomy was performed, with bilateral adnexectomy, partial omentectomy, and pelvic/aortic lymphadenectomy. The patient progressed satisfactorily with no postoperative complications and was discharged from hospital.
2.2. Histopathology of the Surgical Specimen. Cytology was positive for malignant cells. The uterus had no notable histopathological abnormalities. Macroscopically, the left ovary measured $20 \times 20 \times 8 \mathrm{~cm}$, with a smooth, shiny surface (Figure 1(a)). Sectioning revealed a cystic lesion with irregular internal walls, friable vegetation, and solid areas of white tissue. Microscopic examination revealed a mucinous cystadenocarcinoma of the intestinal type with solid, cystic, cribriform, and infiltrating areas with foci of necrosis. Numerous viable $S$. mansoni eggs surrounded by eosinophilic granulomas permeating the neoplastic tissue were found in 2 of the 30 slides examined (Figures 1(b) and 1(c)). Reactive inflammation and the fact that the eggshells were intact indicated that the eggs were viable. There was no fibrosis or calcification.

None of the clinical or complementary examinations to which the patient was submitted showed any signs of parasitic infection, except for the findings of $S$. mansoni eggs in the surgical specimen.

The patient was referred for adjuvant chemotherapy, and a single dose of praziquantel $50 \mathrm{mg} / \mathrm{kg}$ was prescribed to treat her schistosomiasis. She was referred to a center for parasitic infections and was not followed up at this clinic due to the fact that she lives in another state.

\section{Case Report \#2}

This patient, a 47-year-old postmenopausal woman, was hospitalized due to progressive abdominal distension over the previous year. She also reported abdominal pain but no gastrointestinal symptoms, fever, and loss of appetite or weight. At the time of admission to hospital, the patient was complaining of a dry cough.

Physical examination showed the patient to be in an apparently good general state of health and well hydrated, with normal temperature and no signs of anemia, jaundice, or cyanosis. There were no signs of cardiovascular or respiratory abnormalities. The abdomen was distended, with normal bowel sounds and an irregular, voluminous mass extending from the pelvis to $15 \mathrm{~cm}$ above the umbilicus. Gynecological examination showed a hypotrophic cervix, epithelialization, slit-shaped external os with no apparent lesions, and the presence of a yellowish, malodorous secretion. Digital pelvic examination showed a closed, largely immobile cervix, with no pain at manipulation. Bimanual palpation revealed the presence of a large pelvic mass.

CT of the pelvis showed a large, expansive heterogeneous mass, with partially defined, irregular borders, multiple septa, and internal amorphous calcifications, with its epicenter in the pelvic cavity, predominantly to the right, with maximal longitudinal, anteroposterior, and transverse diameters of $20.0,15.3$, and $23.4 \mathrm{~cm}$, respectively.

The results of supplementary tests showed CA-125 levels of $952.93 \mathrm{U} / \mathrm{mL}$, hemoglobin $12.9 \mathrm{~g} / \mathrm{dL}$, hematocrit $37.7 \%$, mean corpuscular volume (MCV) $83.2 \mathrm{fl}$, mean corpuscular hemoglobin (MCH) $28.5 \mathrm{pq}$, mean corpuscular hemoglobin concentration (MCHC) $34.2 \%$, and coefficient of variation of red cell distribution width (RDW-CV) $13.0 \%$. White blood cell count was $7,790 / \mathrm{cm}^{3}$, with $2 \%$ eosinophils $\left(156 / \mathrm{mm}^{3}\right)$. 


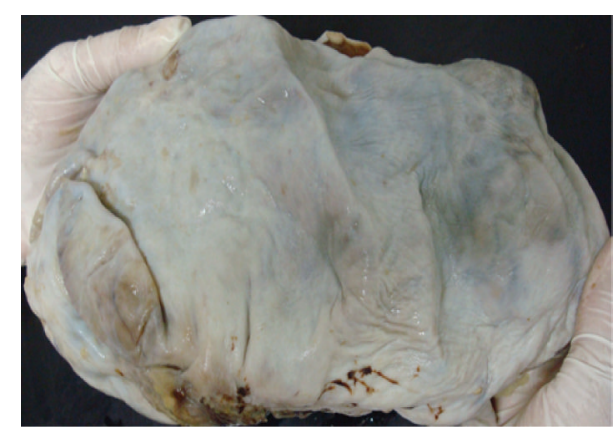

(a)

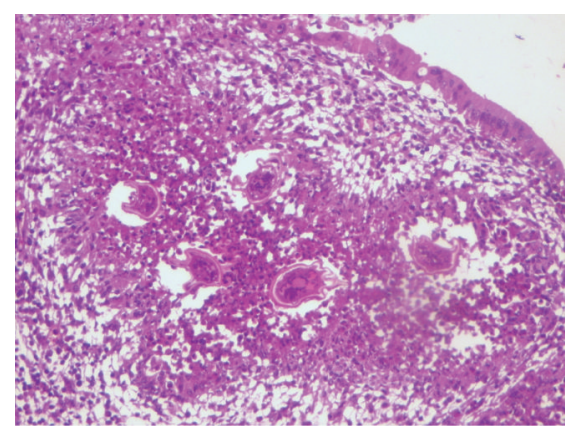

(b)

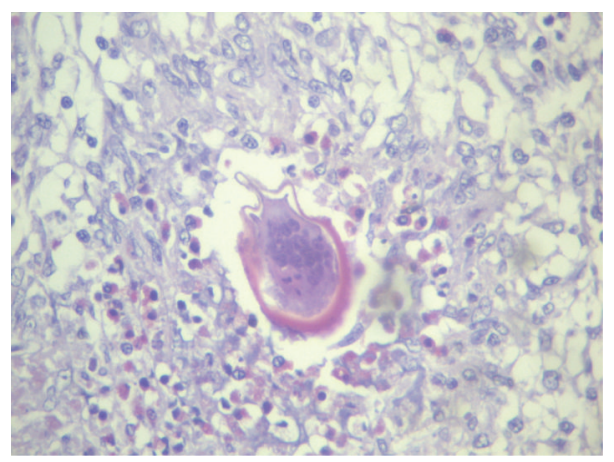

(c)

Figure 1: Case report \#1. (a) Macroscopic view of the left ovary measuring $25 \times 20 \times 8 \mathrm{~cm}$. (b) Viable S. mansoni eggs (hematoxylin-eosin, magnification 40x). (c) Detailed view of a S. mansoni egg (periodic acid-Schiff, magnification 400x).

3.1. Surgery. Exploratory laparotomy was performed through a midline infraumbilical incision, revealing a large pelvic mass of mixed composition occupying almost the entire abdominal/pelvic cavity, extending up to the hypochondrium, adhered to the uterus, adnexa, and bowel. Hysterectomy was performed and included bilateral adnexectomy, partial omentectomy, and pelvic/aortic lymphadenectomy. The patient progressed satisfactorily with no complications following surgery and was released from hospital.

3.2. Histopathology of the Surgical Specimen. Cytology was positive for malignant cells. Macroscopically, the specimen measured $21 \times 17 \times 13 \mathrm{~cm}$ (Figure 2(a)) and weighed 1200 grams. The tumor consisted of various cysts, some with a semisolid content, and others were light brown in color and friable, infiltrating the capsule and exteriorizing part of the cyst. Part of the capsule of the cyst was thickened and hardened. The uterus measured $10 \times 6 \times 5 \mathrm{~cm}$ and weighed 115 grams, with a brownish serous membrane, fibrous adherences, and a brownish, friable mass in the region of the left ovary, which measured $8 \times 8 \mathrm{~cm}$. The histologic sections showed that the mass did not appear to be infiltrating the uterus. The endometrium was $0.2 \mathrm{~cm}$ thick and bleeding. The myometrium was $2 \mathrm{~cm}$ thick, with a small nodule measuring $0.4 \times 0.3 \mathrm{~cm}$. The left fallopian tube measured $4.5 \times 1.3 \mathrm{~cm}$, with a brownish serous membrane and patent lumen. A segment of the omentum measuring $25 \times 8 \times 0.6 \mathrm{~cm}$ was yellowish and firm/elastic. Microscopic examination of the right ovary detected a papillary serous carcinoma, grade $2 / 3$, measuring
$21 \mathrm{~cm}$ at its longest axis, with a solid papillary pattern. Tumor septate consisting of eosinophilic granulomas associated with viable S. mansoni eggs were found (Figures $2(\mathrm{~b})$ and $2(\mathrm{c})$ ). On the left ovary, a papillary serous carcinoma, grade $2 / 3$, was present, measuring $8 \mathrm{~cm}$ at its largest axis. There were no signs of neoplasia in the uterus or in the fallopian tubes. In the omentum, there was metastasis from the multifocal serous carcinoma.

None of the clinical or complementary examinations to which the patient was submitted showed any signs of parasitic infection, except for the findings of S. mansoni eggs in the surgical specimen.

The patient was referred for adjuvant chemotherapy, and a single dose of praziquantel $50 \mathrm{mg} / \mathrm{kg}$ was prescribed to treat her schistosomiasis. She was followed up at a referral center for parasitic infections and by a clinical oncology specialist.

\section{Discussion}

Epithelial tumors originate in the epithelial surface and are classified at anatomopathology as serous, mucinous, clear-cell, endometrioid, or Brenner tumors [11]. Malignant ovarian tumors may be associated with high serum CA125 glycoprotein levels $(\geq 35 \mathrm{U} / \mathrm{mL})$. However, this test is nonspecific, since the levels may also be high in the case of benign ovarian tumors, endometriosis, leiomyomas, and other diseases. Moreover, some patients with ovarian tumors may have low serum CA-125 levels [12]. As shown in the reports of these two cases, CA-125 levels were significantly 


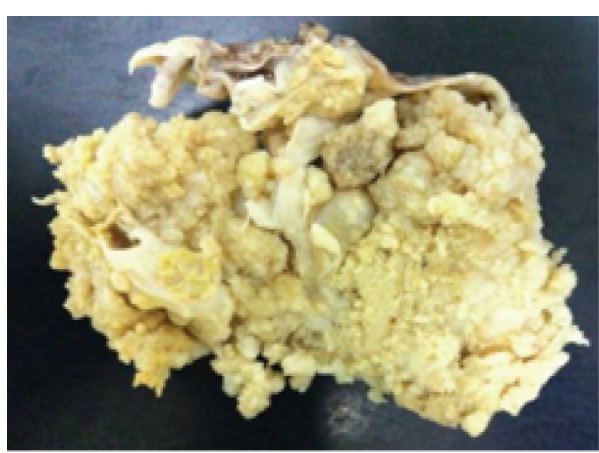

(a)

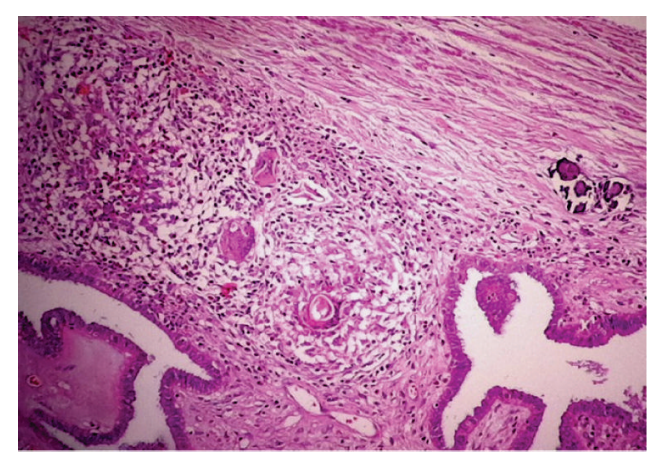

(b)

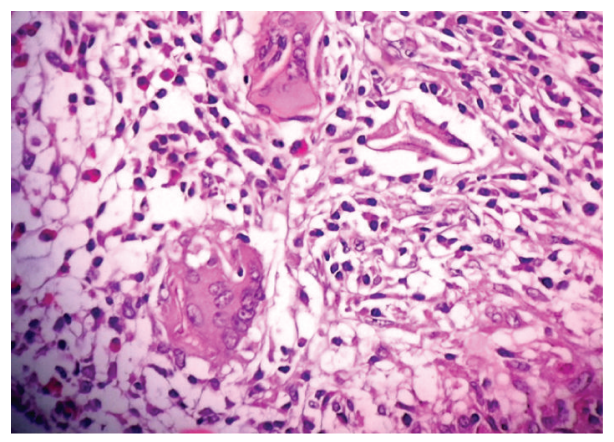

(c)

Figure 2: Case Report \#2. (a) Macroscopic view of the right ovary measuring $21 \times 17 \times 13 \mathrm{~cm}$. (b) Serous carcinoma with granulomas (hematoxylin-eosin, magnification 100x). (c) Viable S. mansoni eggs (hematoxylin-eosin, magnification 400x).

increased in case \#2 (papillary serous carcinoma), while in case \#1 (mucinous cystadenocarcinoma of the intestinal type) the levels of CA-125 were normal.

The two cases reported above involved ovarian carcinomas, with the additional finding of S. mansoni eggs in the surgical specimens from the ovaries.

The biological cycle of schistosomiasis is complex and well defined, with water being the means through which the parasite infects the main host (vertebrate/man). In turn, contaminated human feces in contact with water spread the infection to the intermediate host (invertebrate-the Biomphalaria snail) [13]. The adult parasites live in the blood vessels that connect the bowel to the liver (the hepatic portal system) in the vertebrate host [14].

S. mansoni infestations are referred to as ectopic when the eggs or the adult form of the parasite is found outside the portal system, for example, in the skin, central nervous system, thyroid, myocardium, esophagus, stomach, gall bladder, pancreas, suprarenal, or urogenital tract [15]. These presentations may affect individuals with any parasite load, even years after the initial exposure [16]. The mechanism underlying ectopic migration remains to be clarified. The most widely accepted theory involves the migration of the adult parasites to the pelvic veins. Accordingly, the helminthes would travel in the opposite direction to that of blood flow, thus reaching the terminal portal venules. [17]. Other mechanisms that have been proposed are (a) embolization of the $S$. mansoni eggs through the network of arteries as a consequence of the presence of congenital cardiovascular defects or arteriovenous shunts and (b) egglaying after the migration of the helminthes [17].

The transfer of eggs to pelvic region may generate reactions in the internal genital organs, leading to dyspareunia, vaginal discharge, bleeding, dysmenorrhea, lower abdominal pain, or abdominal/pelvic tumors, all of these being nonspecific findings often reported by gynecologists [18]. The vascularization of the female pelvis is peculiar in that it has numerous anastomoses that drain the female genital organs to the mesenteric venous system and consequently to the portal vein [14]. Some studies have shown that the microvascular network of preovulatory follicles is more developed and extensive compared to that of the other follicles, thus producing more substrates, nutrients, and trophic hormones that permit follicular development and growth. Therefore, vascularization in the female pelvis is distinctive, and the modifications that occur in angiogenesis during reproductive life and pregnancy may facilitate the implantation of ectopic schistosomiasis [19].

Neoplastic processes such as the tumors described here produce vascular endothelial growth factor (VEGF) and fibroblast growth factor (FGF), amongst other substances that permit the proliferation, survival, and differentiation of the endothelial cells, thus generating neovascularization, which is fundamental for the survival and progression of the neoplastic cells [20]. The neoplasms probably serve as a migratory route for the adult parasites and the embolization of eggs. The presence of viable S. mansoni eggs in the ovarian tumors described here strengthens this hypothesis. 
The presence of $S$. mansoni eggs causes inflammation and oxidative stress, which may lead to a poorer prognosis in the case of ovarian tumors. Nevertheless, there is insufficient evidence to confirm the malignization of a benign lesion due to the presence of $S$. mansoni. Further studies should be conducted in endemic areas to confirm this association, since in the majority of cases ectopic schistosomiasis lesions are diagnosed from surgical specimens or after death.

\section{Conclusion}

Studies on the association between S. mansoni and ovarian carcinoma are sparse in the literature; therefore, further studies should be conducted in endemic areas to provide further information on this association and on treatment in order to improve the current situation in which diagnosis in most cases is based on surgical specimens or reached following death.

\section{Conflict of Interests}

The authors declare that there is no conflict of interests associated with this paper.

\section{References}

[1] H. Smith, "Clinical management of ovarian cancer," The New England Journal of Medicine, vol. 345, pp. 152-153, 2001.

[2] M. P. Araújo, A. C. Barros, M. A. Calil et al., "Ovarian mucinous cystadenocarcinoma and systemic sclerosis," Revista Brasileira de Reumatologia, vol. 44, pp. 104-108, 2004.

[3] C. M. Ristow, C. T. Yamamoto, and M. Fávaro, "Risk factors and pathogenesis of malignant epithelial ovarian neoplasm: a literature review," Revista Brasileira de Cancerologia, vol. 52, pp. 185-195, 2006.

[4] H. W. Shappell, M. A. Riopel, A. E. S. Sehdev, B. M. Ronnett, and R. J. Kurman, "Diagnostic criteria and behavior of ovarian seromucinous (endocervical-type mucinous and mixed cell-type) tumors: atypical proliferative (borderline) tumors, intraepithelial, microinvasive, and invasive carcinomas," The American Journal of Surgical Pathology, vol. 26, no. 12, pp. 15291541, 2002.

[5] P. P. Christo, V. A. Zambelli, F. F. Amâncio, M. Oliveira, S. H. Carvalho, and R. C. Said, "Acute encephalitis caused by schistosoma mansoni," Arquivos de Neuro-Psiquiatria, vol. 68, no. 6, pp. 968-970, 2010.

[6] Organização Mundial de Saúde, Esquistossomose, Organização Mundial da Saúde, Geneva, Switzerland, 1996.

[7] S. C. Drummond, L. C. D. S. Silva, R. S. Do Amaral, S. R. SousaPereira, C. M. Antunes, and J. R. Lambertucci, "Morbidity of schistosomiasis mansoni in the state of Minas Gerais, Brazil," Memorias do Instituto Oswaldo Cruz, vol. 101, supplement 1, pp. 37-44, 2006.

[8] J. A. Ariadna, F. Brescia, D. R. Conceição, A. Dias, C. Perônio, and M. M. Esther, "Acompanhamento do ciclo de vida de Schistosoma mansoni (Platyhelminthes: Trematoda) em condições laboratoriais," Revista de Biologia e Ciências da Terra, vol. 1, no. 2, 2001.

[9] W. L. S. Poderoso, W. B. De Santana, E. F. Da Costa, R. Cipolotti, and R. Fakhouri, "Ectopic schistosomiasis: description of five cases involving skin, one ovarian case and one adrenal case," Revista da Sociedade Brasileira de Medicina Tropical, vol. 41, no. 6, pp. 668-671, 2008.

[10] H. D. Mazigo, G. C. Giiti, M. Zinga, J. Heukelbach, and P. Rambau, "Schistosomal peritonitis secondary to perforated appendicitis," Brazilian Journal of Infectious Diseases, vol. 14, no. 6, pp. 628-630, 2010.

[11] M. C. Sánchez, J. Sáenz, and S. Ostiz, "Multidisciplinary management of ovarian epithelial cancer. Radiological diagnosis," Anales del Sistema Sanitario de Navarra, vol. 34, no. 2, pp. 275288, 2011.

[12] J.-E. Shin, H. J. Choi, M.-H. Kim, and K.-S. Cho, "The serum CA-125 concentration data assists in evaluating CT imaging information when used to differentiate borderline ovarian tumor from malignant epithelial ovarian tumors," Korean Journal of Radiology, vol. 12, no. 4, pp. 456-462, 2011.

[13] F. R. Fonseca, T. S. Saraiva, C. C. Freitas et al., "Desenvolvimento de um índice hidrológico para aplicação em estudos de distribuição da prevalência de esquistossomose em Minas Gerais," in Anais do XIII Simpósio Brasileiro de Sensoriamento Remoto, p. 2590, INPE, Florianópolis, Brasil, April 2007.

[14] N. Katz and K. Almeida, "Esquistossomose, xistosa, barriga d'água," Ciência e Cultura, vol. 55, pp. 38-43, 2003.

[15] T. P. Batista, J. J. R. De Andrade, and L. A. M. Da Fonte Filho, "Schistosoma mansoni: an unusual cause of ovarian pseudotumor," Archives of Gynecology and Obstetrics, vol. 281, no. 1, pp. 141-143, 2010.

[16] L. do Carmo Almeida, M. G. de Oliveira, F. M. C. Pereira, and J. de Bessa Jr., "From incidentaloma to suspicion of malignancy: the diverse clinical presentation of gonadal Schistosomiasis mansoni," Case Reports in Infectious Diseases, vol. 2013, Article ID 515910, 3 pages, 2013.

[17] K. M. T. Nunes, A. E. C. Cardoso, F. D. S. G. Pereira, L. H. C. Batista, and R. L. S. Houly, "Ectopic cutaneous schistosomiasis-case report," Anais Brasileiros de Dermatologia, vol. 88, no. 6, pp. 969-972, 2013.

[18] H. Feldmeier, R. C. Daccal, M. J. Martins, V. Soares, and R. Martins, "Genital manifestations of schistosomiasis mansoni in women: important but neglected," Memorias do Instituto Oswaldo Cruz, vol. 93, supplement 1, pp. 127-133, 1998.

[19] A. C. Filho, R. F. Neves, C. B. Gusmão, F. T. Saade, I. R. Dalvi, and T. C. Leo, "Genital schistosomiasis: mucinous cystadenocarcinoma of the ovary containing Schistosoma mansoni eggs," The Journal of Tropical Medicine and Parasitology, vol. 33, no. 1, pp. 36-40, 2010.

[20] M. Duarte, A. Longatto Filho, and F. C. Schmitt, "Angiogenesis, haemostasis and cancer: new paradigms and old concerns," Jornal Brasileiro de Patologia e Medicina Laboratorial, vol. 43, no. 6, pp. 441-449, 2007. 


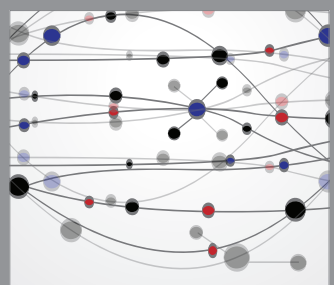

The Scientific World Journal
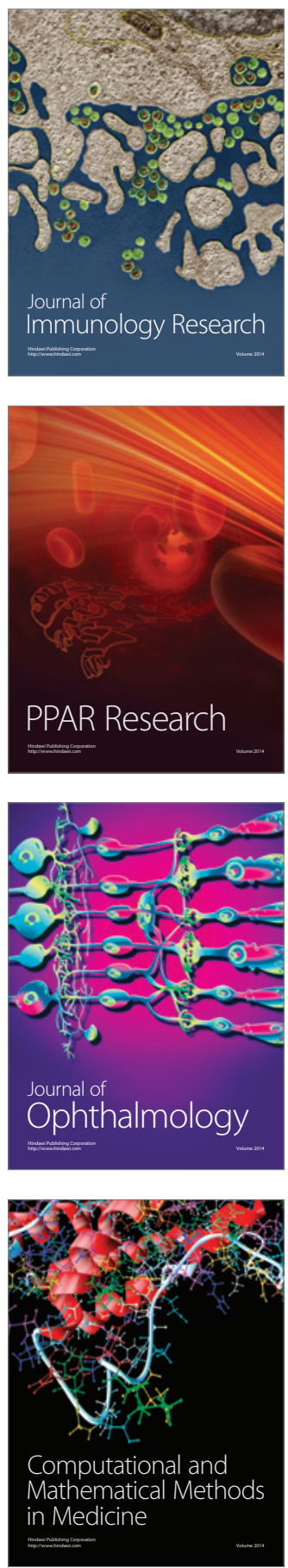

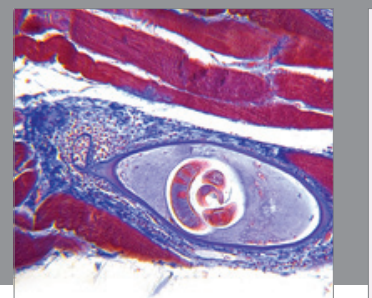

Gastroenterology

Research and Practice
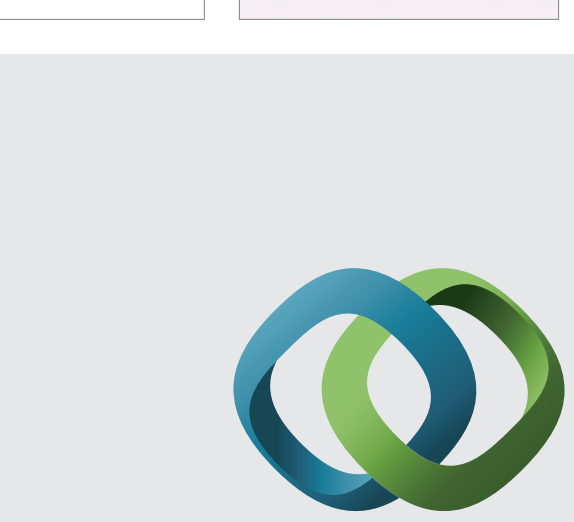

\section{Hindawi}

Submit your manuscripts at

http://www.hindawi.com
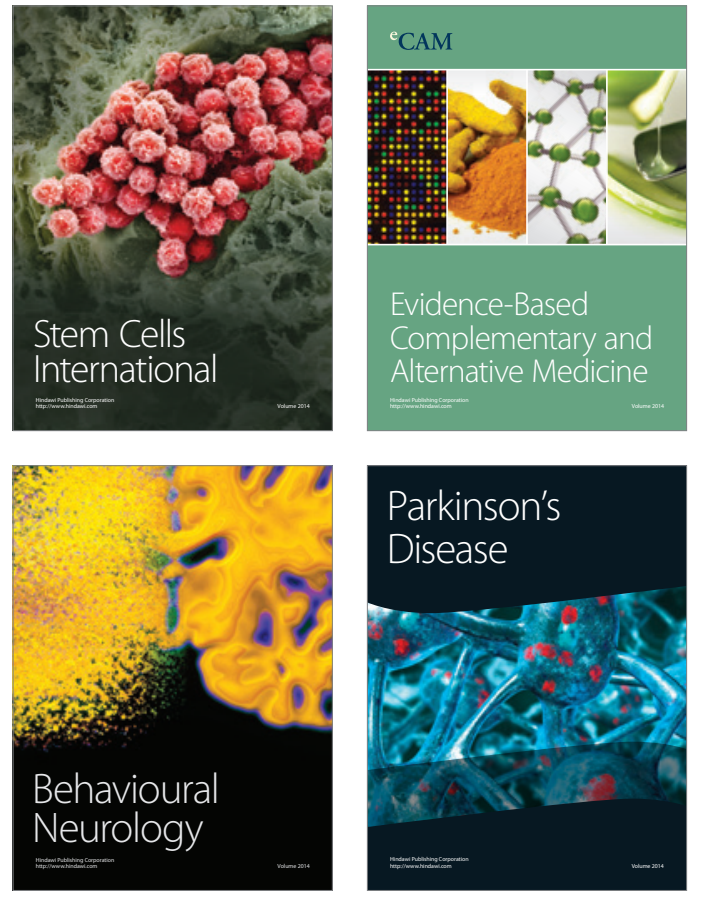
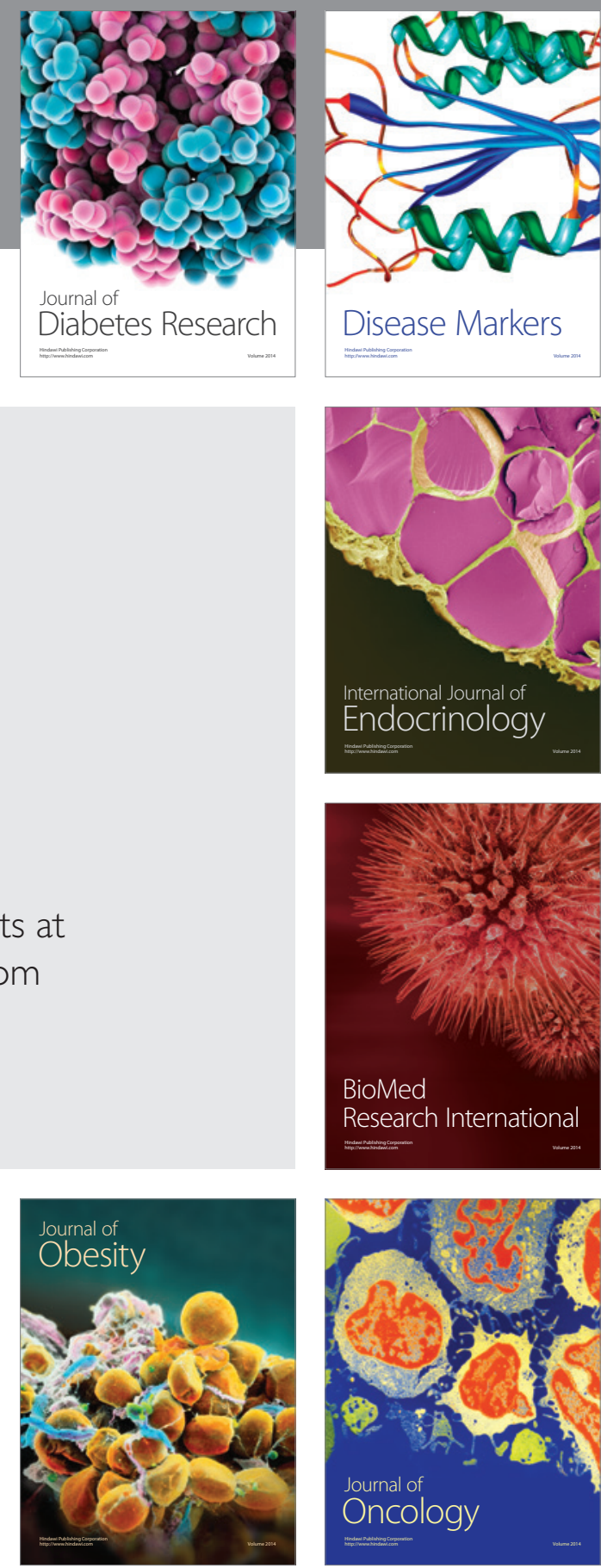

Disease Markers
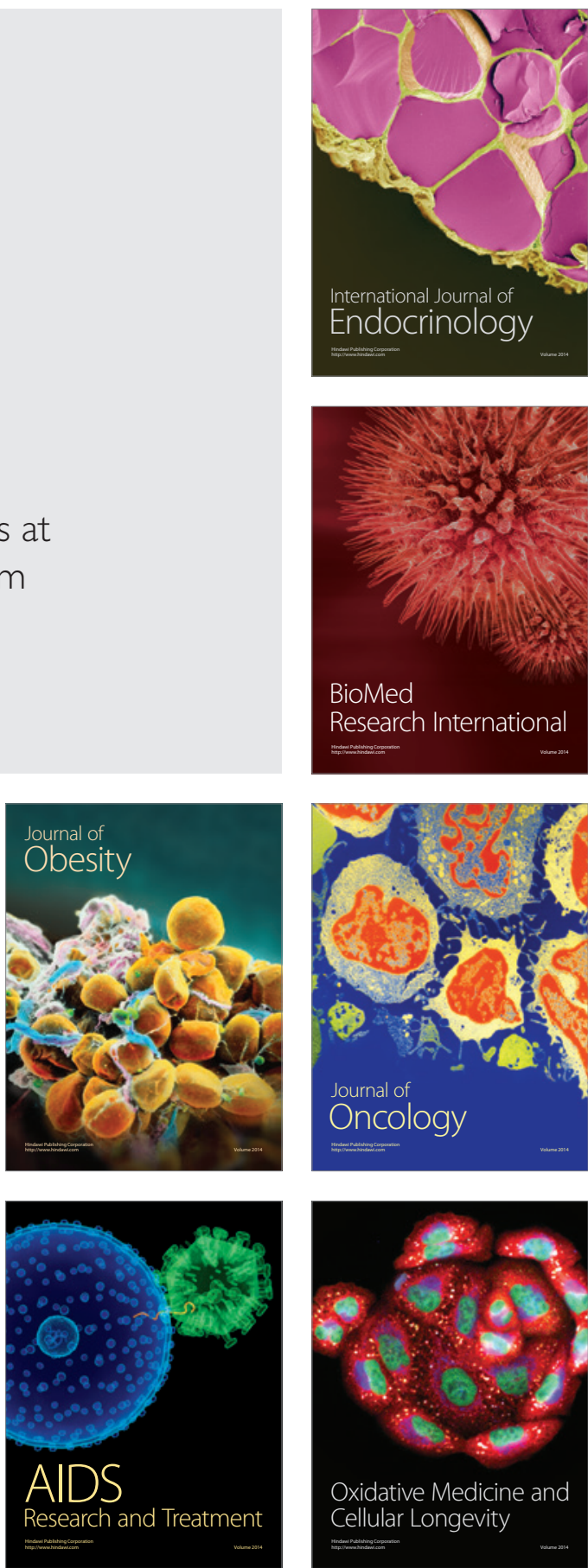